\title{
Analysis of immunoglobulin light-chain mRNA in gastric malignant lymphoma using new highly sensitive in situ hybridization method
}

\author{
Yoshiaki SumiYoshi ${ }^{1}$, Masahiro Kikuchi ${ }^{2}$, Yuichi Yamashita $^{1}$, Takafumi Maekawa $^{1}$, and Takayuki Shirakusa ${ }^{1}$ \\ ${ }^{1}$ Second Department of Surgery, Fukuoka University School of Medicine, 7-45-1 Nanakuma, Jonan-ku, Fukuoka 814-0180, Japan \\ ${ }^{2}$ First Department of Pathology, Fukuoka University School of Medicine, Fukuoka, Japan
}

\begin{abstract}
:
Background. To analyze B-cell monoclonality, we need fresh materials for the Southern blotting method. In situ hybridization (ISH) for the detection of immunoglobulin light-chain mRNA can be used in formalin-fixed and paraffinembedded tissues. However, it is difficult to detect low levels of mRNA copies. So we must develop new highly sensitive in situ hybridization methods to diagnose gastric malignant lymphoma.

Methods. We analyzed materials from 15 patients with gastric malignant lymphoma, using a new highly sensitive ISH method, and compared the results with those of a conventional method.

Results. With this new method, 13 of 15 cases were shown to have monotypic cytoplasmic signals, and monoclonality was detected in 3 of 4 cases of mucosa-associated lymphoid tissue (MALT) lymphoma.

Conclusions. The accuracy of endoscopic biopsies is not satisfactory. However, the detection of immunoglobulin light chain mRNA, using the new highly sensitive ISH method with a non-radioactive isotope oligonucleotide probe, can be used to diagnose gastric malignant lymphoma even when conventional immunoglobulin light-chain mRNA or proteins alone cannot demonstrate the clonality.
\end{abstract}

Key words: in situ hybridization, gastric malignant lymphoma, immunoglobulin light-chain mRNA, MALT, ImmunoMax

\section{Introduction}

Malignant gastric lymphomas constitute approximately $1 \%-7 \%$ of malignant gastric neoplasms and are the most common non-epithelial malignancies of the

Offprint requests to: $\mathrm{Y}$. Sumiyoshi

Received for publication on Oct. 7, 1998; accepted on Jan. 11, 1999 stomach [1-3]. The endoscopic appearance of gastric lymphomas varies widely, and it is often difficult to distinguish between a benign lymphoproliferative disorder and a malignant lymphoma, even with histologic evaluation. Since more than $90 \%$ of primary gastric lymphomas are of B-cell origin, detection of immunoglobulin gene rearrangement could provide information for distinguishing malignant neoplastic from reactive diseases [4,5]. Southern blotting is limited for diagnostic work because it is time-consuming and complex, and requires the use of radioactive isotopes and large amounts of DNA. In addition, it is not well suited to the study of formalin-fixed and paraffin-embedded material because of the consequent DNA degeneration [6-9]. Although immunohistologic studies for the detection of immunoglobulin light chains have been widely employed to determine monotypic restriction, the results have not been consistently successful, particularly with formalin-fixed and paraffin-embedded sections [10,11]. Recently, new techniques for the detection of immunoglobulin light chain mRNA have been reported $[12,13]$. However, these new methods of in situ hybridization (ISH) present some problems that must be solved. To address these issues, we developed a new highly sensitive ISH method that is an adaptation of the new maximized immunohistological method (ImmunoMax) [14]. To prove the clonality of gastric malignant lymphoma in formalin-fixed and paraffin-embedded tissue, we performed ISH for immunoglobulin light-chain mRNA and compared the results with those of immunohistological staining and a conventional ISH method.

\section{Materials and methods}

\section{Tissue and immunohistochemical study}

Formalin-fixed paraffin-embedded specimens from the surgically resected gastric malignant lymphomas of 15 
patients were obtained from our files accrued from 1978 to 1996. The histological diagnoses of all 15 specimens were evaluated and classified by pathologists according to the Lymphoma Study Group (LSG) classification [15]. All specimens were fixed in $10 \%$ formalin, embed-

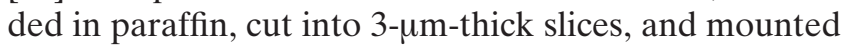
on poly-L-lysine coated slides. All slides were stained with hematoxylin-eosin, Giemsa, periodic acid-Schiff, and silver impregnation for reticulin fibers. Additionally, immunohistological studies were performed by the labeled-streptavidin-biotin method (LSAB), using the monoclonal antibodies UCHL-1 (CD45RO; Dakopatts, Glostrup, Denmark), MT-1 (CD43; BioScience, Emmenbrucke, Switzerland); L-26, (CD20, Dakopatts), Anti bcl-2 (Dakopatts), CD5 (BectonDickinson, Mountain View, CA, USA), immunoglobulin kappa light chain (Dakopatts), and immunoglobulin lambda light chain (Dakopatts).

\section{Conventional in situ hybridization}

Conventional ISH, based on the method of Pringle et al. [12], was conducted using cocktails of fluorescein isothiocyanate (FITC)-labeled oligoprobes, which were specific for human kappa and lambda immunoglobulin light chain mRNA (Dakopatts). Hybridization products were detected using a monoclonal mouse anti-FITC antibody, biotinylated horse anti-mouse immunoglobulin, and streptavidin biotin complex-alkaline phosphatase, and visualized with the new fuchsin.

To confirm the specificity of this ISH method, we used negative control slides which were submitted to RNAse treatment at $37^{\circ} \mathrm{C}$ for $1 \mathrm{~h}$.

\section{New highly sensitive in situ hybridization}

The same probes used for the conventional method described above were used for the new highly sensitive ISH method. For prehybridization treatment, the slides were put in $0.2 \mathrm{~N} \mathrm{HCl}$ for $10 \mathrm{~min}$ and then in $50 \mu \mathrm{g} / \mathrm{ml}$ proteinase $\mathrm{K}$ solution for $10 \mathrm{~min}$, and finally in $1.5 \%$ $\mathrm{H}_{2} \mathrm{O}_{2}$ for $10 \mathrm{~min}$ at room temperature. After dehydration, the slides were air-dried. Next, $100 \mu \mathrm{l}$ of FITClabeled oligoprobe cocktails was added to the slides and they were incubated at $37^{\circ} \mathrm{C}$ for $3 \mathrm{~h}$. The slides were washed three times in Tris buffered saline (TBS) and left at room temperature for $5 \mathrm{~min}$. Diluted mouse monoclonal anti-FITC antibody was prepared in $20 \%$ normal horse serum $/ 2 \%$ casein TBS, added to the slides, and the mixture incubated overnight at $4^{\circ} \mathrm{C}$. Next, biotinylated horse anti-mouse immunoglobulin was added and incubated at room temperature for $30 \mathrm{~min}$. Then streptavidin-biotin complex-horseradish peroxidase (Dako kit) was added and the mixture left at room temperature for $30 \mathrm{~min}$. Next, diluted biotinylated tyramine (Dupont, Wilmington, DE, USA) was prepared in $0.035 \% \mathrm{H}_{2} \mathrm{O}_{2} / \mathrm{TBS}$ and added to each slide at room temperature $(10 \mathrm{~min})$. Finally, streptavidin-biotin complex-alkaline phosphatase (Dako kit) was added at room temperature $(30 \mathrm{~min})$. A staining solution was prepared with the new fuchsin substrate and incubated for $10 \mathrm{~min}$ at room temperature to give an insoluble red color-reaction product. Finally, counter-staining with hematoxylin was performed for approximately $5 \mathrm{~min}$.

For negative control slides we used the same procedure as tht for the conventional ISH method.

\section{Results}

In this series, we used formalin-fixed and paraffinembedded tissues from 15 patients with surgically resected, gastric malignant lymphoma. The clinical findings of these patients are summarized in Table 1, and the results of immunohistochemical study, conventional ISH, and the new highly sensitive ISH are summarized in Table 2. The patients' ages ranged from 36 to 76 years (mean, 53.0 years). The ratio of men to women was 8:7. According to the LSG classification, 7 patients had diffuse large type; 3 , diffuse mixed type; 4 , diffuse medium type; and 1, diffuse and follicular large type. In 4 patients whose disease was identified as diffuse medium type by the LSG classification, mucosa-associated lymphoid tissue (MALT) lymphoma was identified histologically.

\section{Immunohistological study}

With the monoclonal antibodies against immunoglobulin light-chains, monotypic restriction was observed in 8 of the 15 cases $(53.3 \%)$. We did not observe monoclonality in the MALT lymphoma cases. Other immunohistological studies are summarized in Table 3.

\section{Conventional in situ hybridization}

Monoclonal restriction was shown in 7 of the 15 cases (46.7\%), compared with 8 of 15 in the immunohistological results. However, 1 case of monoclonality was identified among the MALT lymphoma cases.

\section{New highly sensitive in situ hybridization}

Monotypic cytoplasmic mRNA signals were recognized in 13 of the 15 cases $(86.7 \%)$. Among the 4 MALT lymphoma cases, we identified monoclonal restriction of the immunoglobulin light chain in 3 cases. (Fig. 1A, B) 
Table 1. Summary of clinical charcteristics

\begin{tabular}{|c|c|c|c|c|c|}
\hline Patient no. & Age (years) & Sex & $\begin{array}{c}\text { Surgery date; } \\
\text { year/month/day }\end{array}$ & $\begin{array}{l}\text { Surgery (type of } \\
\text { gastrectomy) }\end{array}$ & Histology \\
\hline 1 & 36 & $\mathrm{~F}$ & 94.04 .06 & Total & Diffuse mixed \\
\hline 2 & 41 & $\mathrm{~F}$ & 98. 06. 01 & Distal & Diffuse large \\
\hline 3 & 44 & $\mathrm{~F}$ & 87. 07. 01 & Total & Diffuse large \\
\hline 4 & 47 & $\mathrm{~F}$ & 78.03 .29 & Distal & Diffuse medium \\
\hline 5 & 48 & $\mathrm{~F}$ & 84. 04. 02 & Total & Diffuse medium \\
\hline 6 & 50 & $\mathrm{~F}$ & 96.03 .11 & Distal & Diffuse large \\
\hline 7 & 57 & $\mathrm{~F}$ & 89. 07.03 & Total & Diffuse medium \\
\hline 8 & 61 & M & 90.09 .26 & Total & Diffuse large \\
\hline 9 & 62 & M & 93.06 .28 & Total & Diffuse mixed \\
\hline 10 & 62 & M & 87.12 .26 & Distal & Diffuse medium \\
\hline 11 & 63 & M & 90.08 .08 & Total & Diffuse large \\
\hline 12 & 66 & M & 80.11. 19 & Total & Diffuse large \\
\hline 13 & 72 & M & 86.04 .25 & Total & Diffuse large \\
\hline 14 & 72 & M & 82.12 .04 & Distal & Diffuse mixed \\
\hline 15 & 76 & M & 86. 03.12 & Distal & Diffuse and follicular large \\
\hline
\end{tabular}

Table 2. Comparison of phenotype results

\begin{tabular}{|c|c|c|c|c|}
\hline Patient no. & Histology & Immunohistology & Conventional ISH & New highly sensitive ISH \\
\hline 1 & Diffuse mixed & Lambda & Lambda & Lambda \\
\hline 2 & Diffuse large & Карра & Kappa & Kappa \\
\hline 3 & Diffuse large & Unknown & Lambda & Lambda \\
\hline 4 & Diffuse medium & Unknown & Unknown & Unknown \\
\hline 5 & Diffuse medium & Unknown & Unknown & Kappa \\
\hline 6 & Diffuse large & Lambda & Unknown & Lambda \\
\hline 7 & Diffuse medium & Unknown & Kappa & Kappa \\
\hline 8 & Diffuse large & Kappa & Kappa & Kappa \\
\hline 9 & Diffuse mixed & Unknown & Unknown & Lambda \\
\hline 10 & Diffuse medium & Unknown & Unknown & Kappa \\
\hline 11 & Diffuse large & Kappa & Unknown & Unknown \\
\hline 12 & Diffuse large & Lambda & Lambda & Lambda \\
\hline 13 & Diffuse large & Lambda & Unknown & Lambda \\
\hline 14 & Diffuse mixed & Unknown & Kappa & Kappa \\
\hline 15 & $\mathrm{D}$ and $\mathrm{F}$ Large & Kappa & Unknown & Карра \\
\hline
\end{tabular}

$\mathrm{D}$ and F, Diffuse and follicular; ISH, in situ hybridization

Table 3. Results of immunohistological study

\begin{tabular}{lccccc}
\hline & \multicolumn{5}{c}{ Monoclonal antibodies } \\
\cline { 2 - 6 } Patient no. & UCHL-1 & MT-1 & L-26 & Anti-bcl-2 & CD5 \\
\hline 1 & - & - & + & - & - \\
2 & - & - & + & - & - \\
3 & - & - & + & - & - \\
4 & - & - & + & - & - \\
5 & - & - & + & - & - \\
6 & - & - & + & - & - \\
7 & - & - & + & - & - \\
8 & - & - & + & - & - \\
9 & - & - & + & - & - \\
10 & - & - & + & - & - \\
11 & - & - & + & - & - \\
12 & - & - & + & - & - \\
13 & - & - & + & - & - \\
14 & - & - & + & - & - \\
15 & - & - & + & + & - \\
\hline
\end{tabular}

\section{Discussion}

The diagnosis of lymphoma can often be difficult when only routine morphologic examination is used. Immunohistochemical study has been used to detect immunoglobulin light-chain restriction, which facilitates diagnosis because almost all primary malignant gastric lymphomas are of B-cell origin $[5,7,10,16]$. However, as cell membrane immunoglobulins can be optimally immunostained only in cryostat sections of fresh tissue, the advantages of using immunohistochemistry with routinely processed sections are limited. Furthermore, difficulties in interpretation have arisen because of the frequent absence of staining and the presence of extracellular immunoglobulins, which obscure staining patterns [17]. 


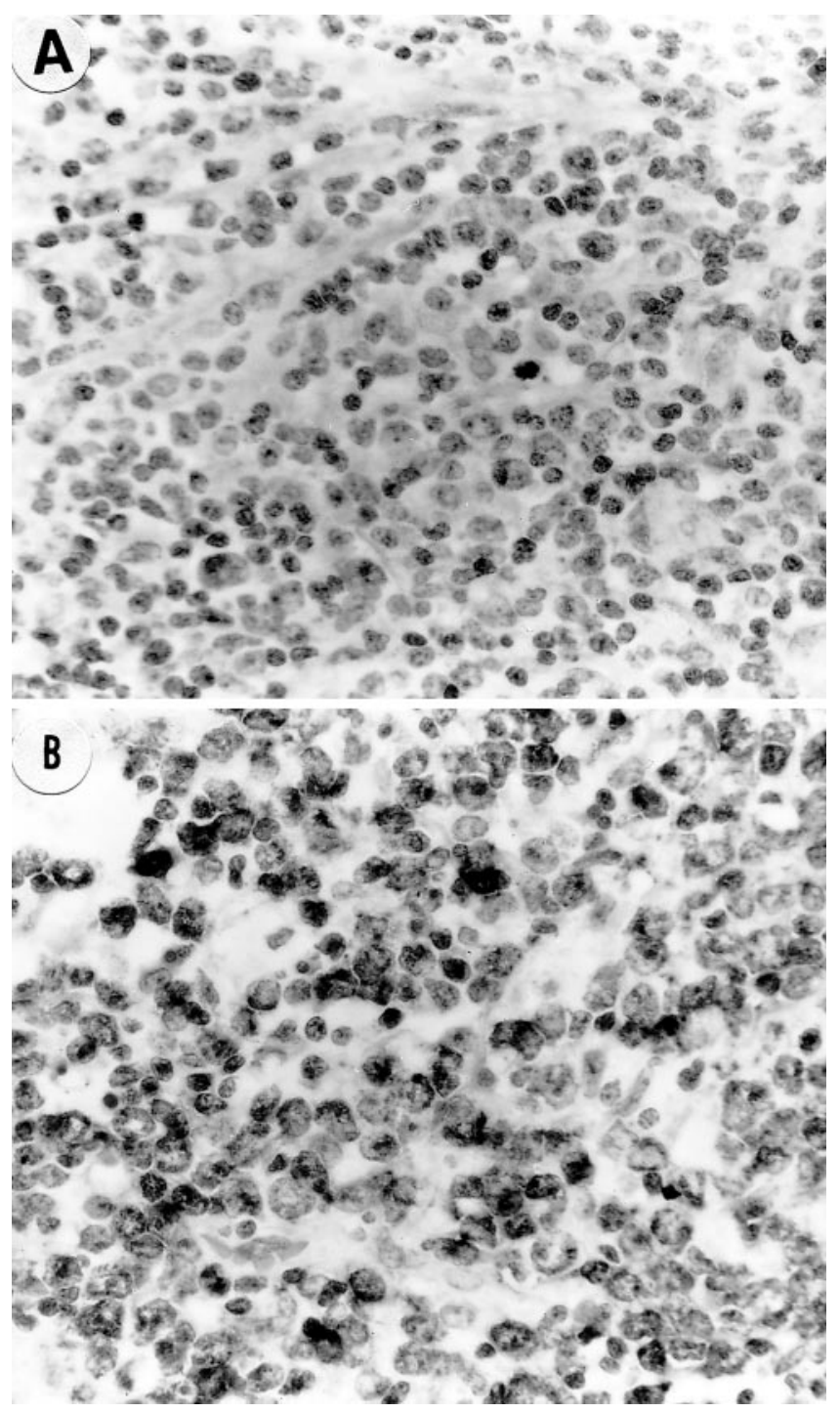

Fig. 1A,B. In situ hybridization (ISH) with gastric malignant lymphoma (mucosa-associated lymphoid tissue [MALT] lymphoma) using fluorescein isothiocyanate-labeled oligonucleotide cocktail probe for A Lambda and B Kappa light-chain mRNAs. Almost all lymphoma cells expressed positive signals for Kappa immunoglobulin light chain mRNA

Some authors have reported that the analysis of immunoglobulin heavy chain rearrangement by a polymerase chain reaction (PCR) method is valuable and that this is the most sensitive method for the diagnosis of gastric malignant lymphoma [18,19]. However, the ISH method is useful, even if the sensitivity for detection of monoclonality for immunoglobulin is less than that with PCR. The greatest advantage of ISH over PCR could be the ability to detect signals with cellular accuracy. Secondly, although a "negative" result with PCR does not always mean that the lesion is polyclonal, ISH can determine polyclonal proliferation of lympho-

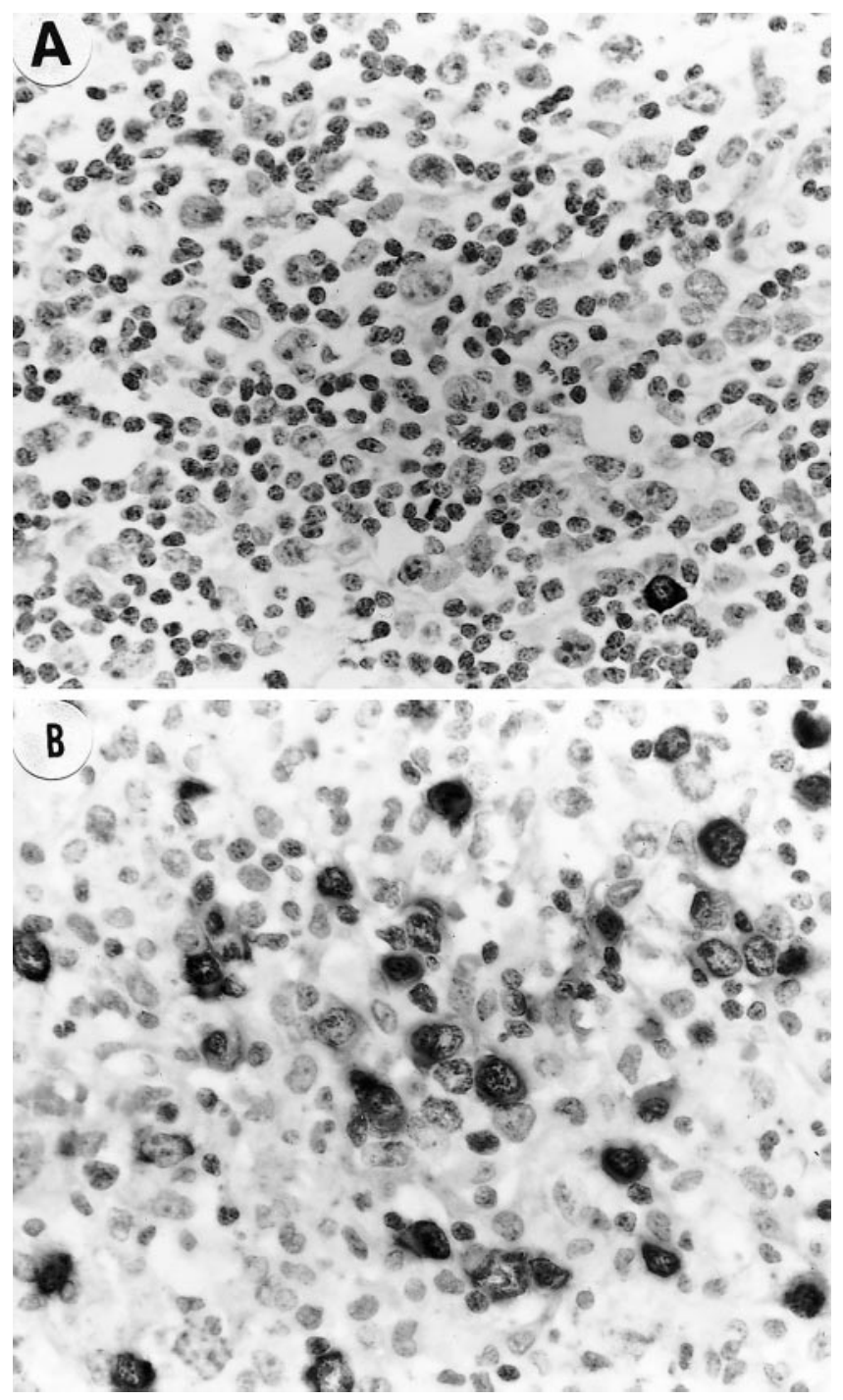

Fig. 2A,B. ISH detection of A Kappa and B Lambda lightchain mRNA in large cell-type gastric malignant lymphoma, intermingled with normal small lymphocytes. The lymphoma cells and normal small lymphocytes are negative for Kappa immunoglobulin light chain mRNA, although the only normal plasma cells are strongly positive (A). However, only the tumor cells are strongly positive for Lambda immunoglobulin light-chain mRNA (B)

cytes as well as monoclonal involvement of a lymphoid lesion (Fig. 2A,B).

ISH methods enable the detection of monotypic immunoglobulin light-chain mRNA in formalin-fixed, paraffin-embedded sections. The oligonucleotide probe, in particular, can be adapted to ISH, especially in paraffin sections $[12,13]$. Because of their small size, oligonucleotide probes readily penetrate paraffin-embedded sections, and mRNA can be detected readily if adequate amounts of mRNA transcripts are present [20,21]. However, the sensitivity of an oligonucleotide probe 
tends to be lower than that of other probes, such as DNA or RNA probes. Although radioactively labeled probes are extremely sensitive for ISH studies, especially when mRNA transcripts are present at low levels, the routine laboratory use of radioactive materials presents obvious problems. In addition, results from a radioactively labeled probe are not available for approximately 2 weeks, whereas results from a nonradioactive isotope (RI) probe are obtained within 2 or 3 days. Accordingly, we need a new method to increase the sensitivity of ISH using a non-RI oligonucleotide probe. In the ImmunoMax method established by Merz et al. [14], combination of the antigen retrieval steps with the biotinylated tyramine enhancement step resulted in a 100- to 10000 -fold boost in sensitivity without loss of specificity. We have used this method (ImmunoMax) in combination with ISH for detecting low quantities of mRNA with a non-RI oligonucleotide probe.

Other studies have reported that the monoclonality of gastric malignant lymphoma can be detected better with an ISH study than with an immunohistochemical study. However, in our results, the conventional ISH method showed a lower detection rate than the immunohistochemical method. The reason for the poor ability of the ISH method to demonstrate monoclonality may be related to the following factors: (1) The immunoglobulin-light chain mRNA may be destroyed due to formalin fixation and the paraffin embedding procedure, because the RNA is easily destroyed by ubiquitous RNase and may degenerate over the course of routine processing of specimens and during storage of tissue blocks. (2) Radioactively labeled probes were not used. (3) The new fuchsin, which is less sensitive than nitroblue tetrazolium (NBT)/5-bromo-4-chloro-3indolylphosphate (BCIP), was used.

In our study, there were only four cases of MALT lymphoma and they were categorized as diffuse medium cell type according to the LSG classification [15]. We know that the marginal zone cells and MALT lymphoma cells show a faint reaction for immunohistological staining and ISH of immunoglobulin light chains [22,23]. Perhaps the MALT lymphomas could not be proven to demonstrate clonality for immunoglobulin light chains due to the low copy number of mRNA in the MALT lymphoma cells; this low number is because the MALT lymphoma cells are in an early differentiation phase, in which immunoglobulin light-chain production has either not yet begun or has just started $[24,25]$. Conclusive proof will require examination of more MALT cases. However, using our new highly sensitive ISH method, we were able to demonstrate clonality by immunoglobulin light-chain restriction, and we believe that this method will aid in the diagnosis of gastric malignant lymphoma, particularly MALT lymphoma, in formalin-fixed, paraffin-embedded materials.

\section{References}

1. Cogliatti SB, Schmid U, Schumacher U, Eckert F, Hansmann M, Hedderich $\mathrm{J}$, et al. Primary B-cell gastric lymphoma: A clinicopathological study of 145 patients. Gastroenterology 1991;101:1159-70.

2. Dragosics B, Bauer P, Radaszkiewicz T. Primary gastrointestinal non-Hodgkin's lymphomas. A retrospective clinicopathologic study of 150 cases. Cancer 1985;55:1060-73.

3. Herrmann R, Panahon AM, Barcos MP, Walsh D, Stutzman L. Gastrointestinal involvement in non-Hodgkin's lymphoma. Cancer 1980;46:215-22.

4. Berger F, Coiffier B, Bonneville C. Gastrointestinal lymphomas. Immunohistologic study of 23 cases. Am J Clin Pathol 1987;88: 707-12.

5. Isaacson P, Spencer J, Finn T. Primary B-cell gastric lymphoma. Hum Pathol 1986;17:72-82.

6. Cleary M, Chao J, Warnke R, Sklar J. Immunoglobulin gene rearrangement as a diagnostic criterion of B-cell lymphoma. Proc Natl Acad Sci USA 1984;81:593-7.

7. Eimoto T, Futami K, Naito H, Takeshita M, Kikuchi M. Gastric pseudolymphoma with monotypic cytoplasmic immunoglobulin. Cancer 1985;55:788-93.

8. Elghetany MT, Kurec AS, Schuehler K, Forbes BA, Duggan DB, Davey FR. Immunophenotyping of non-Hodgkin's lymphomas in paraffin-embedded tissue sections. A comparison with genotypic analysis. Am J Clin Pathol 1991;95:517-25.

9. Osborne BM, Pugh WC. Practicality of molecular studies to evaluate small lymphocytic proliferations in endoscopic gastric biopsies. Am J Surg Pathol 1992;16:838-44.

10. Saraga P, Hurlimann J, Ozello L. Lymphomas and pseudolymphomas of the alimentary tract. An immunohistochemical study with clinicopathologic correlations. Hum Pathol 1981;12:71323.

11. Sukpanichnant S, Vnencak-Jones CL, McCaurley TL. Detection of clonal immunoglobulin heavy chain gene rearrangements by polymerase chain reaction in scrapings from archival hematoxylin and eosin stained histologic sections: implications for molecular genetic studies of focal pathologic lesions. Diagn Mol Pathol 1993;2:168-76.

12. Pringle JH, Ruprai AK, Primrose L, Keyte J, Potter L, Close P. In situ hybridization of immunoglobulin light chain mRNA in paraffin sections using biotinylated or hapten-labelled oligonucleotide probes. J Pathol 1990;162:197-207.

13. Weiss LM, Movahed LA, Chen YY, Shin SS, Stroup RM, Bui N, et al. Detection of immunoglobulin light-chain mRNA in lymphoid tissue using a practical in situ hybridization method. Am J Pathol 1990;137:979-88.

14. Merz H, Malisius R, Mannweiler S, Zhou R, Hartmenn W, Orcheschek K, et al. Methods in laboratory investigation "ImmunoMax": a maximized immunohistochemical method for the retrieval and enhancement of hidden antigens. Lab Invest 1995;73:149-56.

15. Harris NL, Jaffe ES, Stein H, Banks PM, Chan JKC, Cleary ML, et al. A revised European-American classification of lymphoid neoplasms. A proposal from the Intestinal Lymphoma Study Group. Blood 1994;84:1361-92.

16. Wolf B, Martin A, Ree H, Banks P, Smith S, Neiman R. NonHodgkin's lymphomas of the gastrointestinal tract. An evaluation of paraffin section immunostaining. Am J Clin Pathol 1990;93:233-9.

17. Taylor C. Lymphoma/hematopathology. In: Taylor C. Immunomicroscopy: a diagnostic tool for the surgical pathologist. Philadelphia: WB Saunders, 1986:70-115. 
18. Ono H, Kondo H, Saito D, Yoshida S, Shirao K, Yamaguchi H, et al. Rapid diagnosis of gastric lymphoma from biopsy specimens: detection of immunoglobulin heavy chain rearrangement by polymerase chain reaction. Jpn J Cancer Res 1993;84:813-7.

19. Inagaki H, Nonaka M, Nagaya S, Tateyama H, Sasaki M, Eimoto $\mathrm{T}$. Monoclonality in gastric lymphoma detected in formalin-fixed, paraffin-embedded endoscopic biopsy specimens using immunohistochemistry, in situ hybridization, and polymerase chain reaction. Diagn Mol Pathol 1995;4:32-8.

20. Lloyd RV, Jin L. In situ hybridization analysis of chromogranin A and $\mathrm{B}$ mRNAs in neuroendocrine tumors with digoxigeninlabeled oligonucleotide probe cocktails. Diagn Mol Pathol 1995;4:143-51.

21. Lloyd RV, Iacangelo A, Eiden LE, Cano M, Jin L, Grimes M. Chromogranin $\mathrm{A}$ and $\mathrm{B}$ messenger ribonucleic acids in pituitary and other normal and neoplastic human endocrine tissues. Lab Invest 1989;60:548-56.

22. Hell K, Pringle J, Hansmann M, Lorenzen J, Collby P, Lander I, et al. Demonstration of light chain mRNA in Hodgkin's disease. J Pathol 1993;171:137-43.

23. Plank L, Hell K, Hansmann M, Pringle J, Lauder I, Fischer R. Reactive versus neoplastic monocytoid B-cell proliferations: In situ hybridization study of immunoglobulin light chain mRNA. Am J Clin Pathol 1995;103:330-7.

24. Isaacson P, Wright D. Extranodal malignant lymphoma arising from mucosa associated lymphoid tissue. Cancer 1984;53:251524.

25. Isaacson P, Spencer J. Malignant lymphoma of mucosa-associated lymphoid tissue. Histopathology 1987;11:445-62. 